\title{
DETERMINATION OF PHENOBARBITAL IN HUMAN PLASMA BY A SPECIFIC LIQUID CHROMATOGRAPHY METHOD: APPLICATION TO A BIOEQUIVALENCE STUDY
}

\author{
Sérgio Luiz Dalmora*, Maximiliano da Silva Sangoi, Daniele Rubert Nogueira e Felipe Bianchini D’Avila \\ Departamento de Farmácia Industrial, Universidade Federal de Santa Maria, 97105-900 Santa Maria - RS, Brasil \\ Ronílson Agnaldo Moreno
}

Synchrophar Assessoria e Desenvolvimento de Projetos Clínicos S/S Ltda., 13070-200 Campinas - SP, Brasil / Faculdade de Ciências Médicas, Universidade Estadual de Campinas, 13083-970 Campinas - SP, Brasil

Carlos Eduardo Sverdloff

Synchrophar Assessoria e Desenvolvimento de Projetos Clínicos S/S Ltda., 13070-200 Campinas - SP, Brasil

Rogério Antonio de Oliveira

Synchrophar Assessoria e Desenvolvimento de Projetos Clínicos S/S Ltda., 13070-200 Campinas - SP, Brasil / Instituto de Matemática e Estatística, Universidade de São Paulo, 05508-900 São Paulo - SP, Brasil

Ney Carter Borges

Synchrophar Assessoria e Desenvolvimento de Projetos Clínicos S/S Ltda., 13070-200 Campinas - SP, Brasil / Faculdade de Ciências Médicas, Universidade Estadual de Campinas, 13083-970 Campinas - SP, Brasil

Recebido em 17/2/09; aceito em 22/6/09; publicado na web em 25/11/09

\begin{abstract}
A liquid chromatography method was developed and validated for the determination of phenobarbital in human plasma using phenytoin as internal standard. The drugs were extracted from plasma by liquid-liquid extraction and separated isocratically on a $\mathrm{C}_{12}$ analytical column, maintained at $35^{\circ} \mathrm{C}$, with water:acetonitrile:methanol $(58.8: 15.2: 26, \mathrm{v} / \mathrm{v} / \mathrm{v})$ as mobile phase, run at a flow rate of $1.2 \mathrm{~mL} / \mathrm{min}$ with detection at $205 \mathrm{~nm}$. The method was linear in the range of 0.1-4 $\mu \mathrm{g} / \mathrm{mL}\left(r^{2}=0.9999\right)$ and demonstrated acceptable results for the precision, accuracy and stability studies. The method was successfully applied for the bioequivalence study of two tablet formulations (test and reference) of phenobarbital $100 \mathrm{mg}$ after single oral dose administration to healthy human volunteers.
\end{abstract}

Keywords: human plasma; liquid chromatography; phenobarbital.

\section{INTRODUCTION}

Epilepsy is among the most common serious neurological disorders worldwide. This disorder can be successfully controlled with a single well-tolerated antiepileptic drug in the majority of cases, ${ }^{1}$ but when monotherapy fails, antiepileptic drugs should be combined. ${ }^{2}$ The seizures of this disease may result in injury and embarrassment, anxiety, unpredictability, and can occasionally kill. With the correct diagnosis and treatment, many patients will have a significant reduction in seizure frequency or be seizure free. ${ }^{3}$

Phenobarbital (Figure 1) is a substituted barbituric acid that acts as a nonselective central nervous system depressant, and is widely used as antiepileptic drug due to advantages including reliability of supply, affordable cost, broad spectrum of action, and ease of use. ${ }^{3,4}$ It is also used for partial and generalized tonic-clonic seizures treatment. ${ }^{5}$

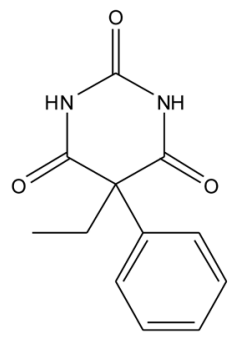

(a)

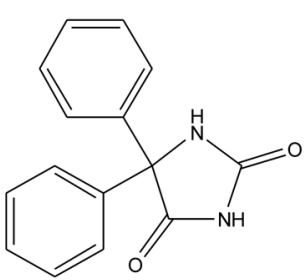

(b)
Figure 1. Chemical structures of phenobarbital (a) and phenytoin, IS (b)

\footnotetext{
*e-mail: sdalmora@terra.com.br
}

The liquid chromatography (LC) methods coupled to mass spectrometry (MS) by atmospheric pressure chemical ionization were carried out by solid phase extraction (SPE) for the determination of phenobarbital in human plasma. ${ }^{6,7}$ The gas chromatography coupled to MS using selected-ion monitoring mode and deuterated internal standard was also applied to biological matrix. ${ }^{8}$ Besides, capillary electrophoresis performed by combining multiwavelength detection with micellar electrokinetic capillary chromatography technique ${ }^{9}$ and micellar liquid chromatography with direct injection of the plasma samples after addition of a SDS solution were also applied to human plasma. ${ }^{10}$ Simultaneous determination of phenobarbital and some drugs in human plasma was performed by different methods to support pharmacokinetic and clinical studies. ${ }^{6-9,11-22}$ A chiral LC method was developed and validated for the determination of phenobarbital and methylphenobarbital enantiomers in human plasma using a $\mathrm{C}_{18}$ precolumn and a chiral column for the enantiomeric separation. ${ }^{23}$ The RP-LC methods were developed with UV detection and using stir bar-sorptive extraction, ${ }^{11}$ liquid-liquid extraction (LLE), ${ }^{12,13,21}$ direct injection of plasma with manual column-switching technique, ${ }^{17} \mathrm{SPE},{ }^{22}$ or protein precipitation. ${ }^{18-20}$ However, some of these methods show disadvantages such as low sensitivity, complicated and extensive sample preparation, and most of them did not demonstrate any applicability for pharmacokinetic or bioequivalence studies. Besides, an RP-LC method using SPE was applied for the oral bioavailability evaluation of two liquid dosage forms in comparison to a phenobarbital tablet, but the validation parameters were not properly described, and the procedure to prepare the samples is time-consuming which could not meet the requirement of highthroughput analysis recommended for the bioequivalence studies. ${ }^{24}$ 
Considering the large number of samples generated and the requirements for the bioequivalence studies, the aim of the present article was to develop and validate a simple, specific and sensitive LC method, using a single step liquid-liquid extraction procedure. This method was applied to a pharmacokinetic analysis of phenobarbital in human plasma supporting a bioequivalence study of two pharmaceutical formulations.

\section{EXPERIMENTAL}

\section{Chemicals and reagents}

The test and reference formulations containing $100 \mathrm{mg}$ of phenobarbital were manufactured by the Cristália Produtos Químicos Farmacêuticos Ltda. (Itapira, SP, Brazil), Batch 07085825 and SanofiAventis (Suzano, SP, Brazil), Batch 701509, respectively, within their shelf life period. Phenobarbital reference substance (Lot J) and phenytoin (Lot J0E090) as internal standard (IS) were purchased from U.S. Pharmacopeia (USA). HPLC grade acetonitrile, methanol and tert-butyl methyl ether were obtained from Tedia (Fairfield, Ohio, USA). For all the analyses, ultrapure water was purified using an Elix 3 coupled to a Milli-Q Gradient A10 system (Millipore, Bedford, MA, USA). All solutions were filtered through a $0.22 \mu \mathrm{m}$ membrane filter (Millipore, Bedford, MA, USA).

\section{Apparatus and chromatographic conditions}

The RP-LC method was carried out on a Shimadzu LC system (Shimadzu, Kyoto, Japan) equipped with a SCL-10A system controller, a LC-10 $\mathrm{AD}_{\mathrm{VP}}$ pump, a DGU-14A degasser, a SIL-10AD autosampler, and a SPD-M10A $\mathrm{AP}_{\mathrm{P}}$ PDA detector. The peak areas were integrated automatically by computer using a Shimadzu Class VP V 6.14 software program. The experiments were carried out on a reversed phase Phenomenex (Torrance, USA) Synergi MAX-RP C analytical column $(150 \times 4.6 \mathrm{~mm}$ I.D., with a particle size of $4 \mu \mathrm{m}$ and pore size of $80 \AA$ ) maintained at $35^{\circ} \mathrm{C}$. The LC system was operated isocratically using a mobile phase of water:acetonitrile:methanol (58.8:15.2:26, v/v/v). This was filtered through a $0.45 \mu \mathrm{m}$ membrane filter (Millipore) and run at a flow rate of $1.2 \mathrm{~mL} / \mathrm{min}$, detected at $205 \mathrm{~nm}$ by a PDA detector. The injection volume was $25 \mu \mathrm{L}$ for both standard and samples. The temperature of the autosampler was kept at $4{ }^{\circ} \mathrm{C}$ and the run time was $12 \mathrm{~min}$.

\section{Standard solutions and calibration curves}

The stock solutions of phenobarbital and IS were prepared by weighing $10 \mathrm{mg}$ of reference material into a $10 \mathrm{~mL}$ individual volumetric flask and dissolving to volume with methanol:water (90:10, v/v), obtaining a concentration of $1 \mathrm{mg} / \mathrm{mL}$. The prepared stock solutions were stored at $2-8{ }^{\circ} \mathrm{C}$ protected from light. Analytical curves of phenobarbital were prepared by spiking blank plasma at concentrations from 0.1 to $4 \mu \mathrm{g} / \mathrm{mL}$. The quality control (QC) samples were prepared in blank plasma at concentrations of 0.25 (low), 1.8 (medium), and $3.4 \mu \mathrm{g} / \mathrm{mL}$ (high), and then divided in aliquots that were stored at $-80{ }^{\circ} \mathrm{C}$ until analysis. The spiked plasma samples (standards and quality controls) were extracted on each analytical batch along with the unknown samples.

\section{Plasma extraction}

For the analysis of phenobarbital, $300 \mu \mathrm{L}$ of each plasma sample was transferred to a $15 \mathrm{~mL}$ glass tube, followed by addition of $50 \mu \mathrm{L}$ of IS solution $(15 \mu \mathrm{g} / \mathrm{mL})$. All samples were mixed by vortex agitation for $30 \mathrm{~s}$. Then, $4 \mathrm{~mL}$ aliquot of extraction solvent, tert-butyl methyl ether, was added using a Dispensette Organic (Brand GmbH, Wertheim, Germany) and vortex mixed for $90 \mathrm{~s}$. The tubes were centrifuged for $15 \mathrm{~min}$ at $2700 \mathrm{rpm}$ and the organic layer was filtered through a Millex GV $0.45 \mathrm{~mm}$ filter unit (Millipore, Bedford, MA, USA) into $15 \mathrm{~mL}$ conical tubes and evaporated under a nitrogen stream while immersed in a $40^{\circ} \mathrm{C}$ water bath. The residues were reconstituted with $300 \mu \mathrm{L}$ of mobile phase. The samples were transferred to auto-sampler vials and $25 \mu \mathrm{L}$ was injected into the $\mathrm{LC}$ system.

\section{Validation of the bioanalytical method}

The method was validated by the determination of the following parameters: specificity, linearity and range, recovery, accuracy, precision, lower limit of quantitation (LLOQ), and stability studies, following the bioanalytical method validation guidelines. ${ }^{25,26}$

Specificity was assessed using six blank human plasma samples, randomly selected, from different sources (including haemolysed and lipemic plasma), that were subjected to the extraction procedure and chromatographed to determine the extent to which endogenous plasma components could interfere in the analysis of phenobarbital or the IS. The results were compared to a solution containing $0.1 \mu \mathrm{g}$ / $\mathrm{mL}$ of phenobarbital.

The analytical curves were constructed from a blank sample (plasma sample processed without IS), a zero sample (plasma processed with IS), and eight concentrations of phenobarbital, including the LLOQ, ranging from 0.1 to $4 \mu \mathrm{g} / \mathrm{mL}$. The peak area ratio of the drug to the IS against the respective standard concentrations was used for plotting the graph and the linearity evaluated by least square regression analysis. The acceptance criteria for each calculated standard concentration was not more than $15 \%$ deviation from the nominal value, except for the LLOQ, which was set at $20 \%$.

The recovery was evaluated by the mean of the response of three concentrations of phenobarbital $(0.25,1.8$, and $3.4 \mu \mathrm{g} / \mathrm{mL})$, each one with addition of $2.5 \mu \mathrm{g} / \mathrm{mL}$ of the IS, dividing the mean of the extracted sample by the mean of the unextracted sample (spiked with the extracted blank plasma residues) at the same concentration level. To eliminate the matrix effects, a comparison of the extracted to the unextracted sample was performed, giving the true recovery.

To evaluate the inter-day precision and accuracy, QC samples were analyzed together with one independent analytical standard curve for 3 days, while intra-day precision and accuracy were evaluated through analysis of the QC samples in six replicates in the same day. Inter- and intra-day precision were expressed as relative standard deviation (RSD). The evaluation of precision and accuracy was based on the criteria that the RSD of each concentration level should be within $15 \%$ of the nominal concentration. ${ }^{26}$

The lowest standard concentration on the analytical curve should be accepted as the limit of quantitation if the following conditions are met: the analyte response at the LLOQ should be at least five times the response compared to blank response and analyte peak (response) should be identifiable, discrete, and reproducible with a precision of $20 \%$ and accuracy of $80-120 \%$. The limit of detection (LOD) was defined by the concentration with a signal-to-noise ratio of 3 .

The stability of phenobarbital in human plasma was evaluated after each storage period and related to the initial concentration as zero cycle (samples that were freshly prepared and processed immediately). The samples were considered stable if the deviation (expressed as percentage bias) from the zero cycle was within $\pm 15 \%$. The freeze-thaw stability of phenobarbital was determined at low, medium, and high QC samples $(n=3)$ over three freeze thaw cycles within 3 days. In each cycle, the frozen plasma samples were thawed at room temperature for $2 \mathrm{~h}$ and refrozen for $24 \mathrm{~h}$. After completion 
of each cycle the samples were analyzed and the results compared with that of the zero cycle. The short term stability was evaluated using three aliquots each of the low, medium, and high unprocessed QC samples kept at room temperature $\left(25 \pm 5^{\circ} \mathrm{C}\right)$ for $8 \mathrm{~h}$, and then analyzed. For the processed sample stability, three aliquots each one of the low, medium, and high QC samples were processed and placed into the autosampler at $5{ }^{\circ} \mathrm{C}$ and analyzed after 24 and $48 \mathrm{~h}$. For the long term stability analysis of phenobarbital, three aliquots of each QC samples were frozen at $-80{ }^{\circ} \mathrm{C}$ for 100 days and then analyzed.

\section{Bioequivalence study}

The study was an open, randomized, two period crossover design with a 42 days washout interval between the doses. Due to the long elimination half-life of phenobarbital, the study was truncated at 72 h, as recommended. ${ }^{27,28}$ Nineteen healthy volunteers of both sexes, aged between 18 and 50 years, and within $15 \%$ of the ideal body weight were selected by clinical evaluation and laboratory tests. The clinical protocol was approved by the local Ethic Committee and the volunteers given written informed agreements to participate in the study. During each period, a single oral dose of phenobarbital (1 tablet $100 \mathrm{mg}$ ) was given with $200 \mathrm{~mL}$ of water after an overnight fast of at least $8 \mathrm{~h}$. Blood samples were collected at $0 \mathrm{~h}$ (predose) and at: $0.25,0.5,0.75,1,1.5,2,3,4,5,6,8,12,24,48$ and $72 \mathrm{~h}$ post dosing. The samples were centrifuged immediately (at $3000 \mathrm{rpm}$ for 15 minutes at $4^{\circ} \mathrm{C}$ ), and the plasma separated and kept frozen at -80 ${ }^{\circ} \mathrm{C}$ in labeled cryogenic tubes until assayed.

\section{Pharmacokinetic and statistical analysis}

The pharmacokinetic parameters of phenobarbital, namely: the maximum plasma concentration $\left(\mathrm{C}_{\max }\right)$ and time point of maximum plasma concentration $\left(\mathrm{T}_{\max }\right.$ ) were obtained directly from the measured data. The area under the phenobarbital plasma concentration time curve $\left(\mathrm{AUC}_{(0-\mathrm{t})}\right)$ was computed using the linear trapezoidal rule.

The pharmacokinetic parameters of phenobarbital were estimated with softwares Microsoft Excel 97, Scientific Work Place, WinNonlin Professional version 5.2, Equivtest version 2.0 and Graph Pad Prism version 5 .

After logarithmic transformation, $\mathrm{AUC}_{(0-\mathrm{t})}$ and $\mathrm{C}_{\max }$ values were subjected to analysis of variance (ANOVA), including the effects of sequence, period and treatment and random effect of subjects (sequence), as described by Chow and Liu. ${ }^{29}$ For the evaluation of bioequivalence, the point estimates and $90 \%$ confidence interval $(\mathrm{CI})$ for the geometric means ratio of $\mathrm{AUC}_{(0-\mathrm{t})}$ and $\mathrm{C}_{\max }$ were constructed, using the residual mean square error obtained from the ANOVA.

The bioequivalence between the two formulations was evaluated based on the $90 \%$ CI transformed back for the geometric mean ratios of $\mathrm{AUC}_{(0-\mathrm{t})}$ and $\mathrm{C}_{\text {max }}$, which are recommended within the 80-125\% interval according to the guidelines. ${ }^{27,28}$

\section{RESULTS AND DISCUSSION}

\section{Optimization of the method}

In order to obtain a simple and effective analytical method, many pretreatment procedures were assayed. Protein precipitation was also tested, showing poor results of recovery and baseline instabilities. Different methods showed that phenobarbital and others antiepileptic drugs could be isolated from plasma by liquid-liquid extraction. Therefore various liquid-liquid extraction procedures were assayed. The presented extraction was chosen because it reliably eliminated interfering material from plasma, with higher recovery of phenobarbital.
To obtain the best chromatographic separation, the mobile phase was optimized to provide sufficient specificity and sensitivity in a short separation time. Various combinations of organic solvents (methanol and acetonitrile) and water were evaluated as mobile phase components. The mobile phase selected resulted in higher specificity, better sensitivity, short analysis time, improving the peak symmetry. Analytical columns with different packing materials including the $\mathrm{C}_{18}$ and $\mathrm{C}_{8}$ were evaluated, and resulted in poor separation of the analytes and the plasma endogenous substances. Then, the Synergi MAX-RP $\mathrm{C}_{12}$ analytical column was selected as it provides the best chromatographic performance and acceptable peak characteristics, including tailing factor, number of theoretical plates and capacity factor. Moreover, good resolution of phenobarbital, IS and the plasma interfering peaks was obtained, thus confirming the specificity of the proposed method. For the selection of the best wavelength detection a PDA detector was used. The optimized conditions of the LC method were validated for the analysis of phenobarbital in human plasma, due to the capability and application for the bioequivalence study.

Representative chromatograms of a blank plasma, plasma spiked with phenobarbital at $0.25 \mu \mathrm{g} / \mathrm{mL}$ and plasma obtained from the human volunteer $3 \mathrm{~h}$ after administration of $100 \mathrm{mg}$ phenobarbital are presented in Figure 2, with peaks symmetry values between 1.25 and 1.44 , assuring the separation and the effectiveness of the quantitation. The resulting retention times were 4.68 (phenobarbital) and $9.75 \mathrm{~min}$ (IS). There were no interfering peaks in drug-free plasma eluting at the retention times of interest. Chromatograms obtained from six different human plasma samples showed that the method is adequately specific.
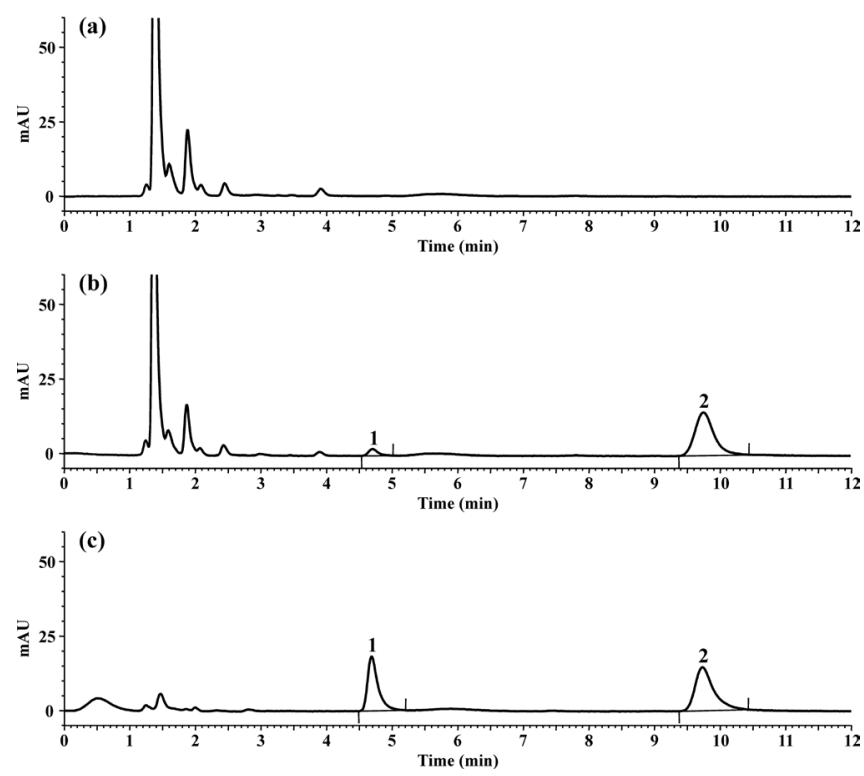

Figure 2. Chromatograms of (a) a blank human plasma; (b) a spiked human plasma of low quality control sample $(0.25 \mu \mathrm{g} / \mathrm{mL})$; (c) a healthy volunteer plasma sample at $3 \mathrm{~h}$ after $100 \mathrm{mg}$ oral dose administration

The proposed method is based on a simple, rapid and efficient sample pre-treatment which allows the determination of phenobarbital in biological matrix with a reasonable elution time and suitable sensitivity, thus fulfilling the criteria required for pharmacokinetic and bioequivalence studies.

\section{Validation of the method}

Linearity was evaluated by six determinations of eight concentrations in the range of $0.1-4 \mu \mathrm{g} / \mathrm{mL}$. The values of the determination 
coefficient $\left(r^{2}=0.9999, y=0.000327 x-0.005366\right)$ indicated significant linearity of the analytical curves for the method. The LLOQ was evaluated in an experimental assay and was found to be $0.1 \mu \mathrm{g} /$ $\mathrm{mL}$ with precision and accuracy lower than $20 \%$. Comparison of the blank and spiked human plasma $(0.1 \mu \mathrm{g} / \mathrm{mL})$ chromatograms indicated that no significant interferences were detected from endogenous substances.

Phenobarbital in human plasma was directly extracted with tertbutyl methyl ether by liquid-liquid extraction. The mean extraction recoveries for the three concentration levels of the QC samples were $94.47 \%$ for phenobarbital and $96.18 \%$ for the IS showing the method suitability (Table 1).

Table 1. Recovery of phenobarbital and phenytoin from human plasma after the extraction procedure

\begin{tabular}{lcc}
\hline $\begin{array}{l}\text { Nominal concentration } \\
(\mu \mathrm{g} / \mathrm{mL})\end{array}$ & \multicolumn{2}{c}{ \% Recovery (mean $\left.\pm \mathrm{RSD}^{\mathrm{a}} \%\right)$} \\
Phenobarbital $^{\mathrm{b}}$ & Phenytoin $^{\mathrm{b}}$ \\
\hline 0.25 & $93.39 \pm 5.33$ & $95.73 \pm 1.45$ \\
1.8 & $94.14 \pm 3.39$ & $95.63 \pm 4.32$ \\
3.4 & $95.89 \pm 1.93$ & $97.17 \pm 2.03$ \\
Mean & $94.47 \pm 1.36$ & $96.18 \pm 0.89$ \\
\hline
\end{tabular}

${ }^{\mathrm{a}} \mathrm{RSD}=$ Relative standard deviation. ${ }^{\mathrm{b}}$ Mean of six replicates

The intra-day accuracy of the method was within 99.49 and $104.56 \%$ with a precision of $1.13-4.14 \%$. The inter-day accuracy was within 98.51 and $103.98 \%$ with RSD of $2.35-3.05 \%$ (Table 2). The data show that the method possesses adequate repeatability and reproducibility.

Phenobarbital was stable in neat plasma for up to $8 \mathrm{~h}$ at room temperature (short-term) and also after three freeze thaw cycles, demonstrating that human plasma samples could be thawed and refrozen without compromising the integrity of the samples. Plasma samples were stable for at least 100 days at $-80{ }^{\circ} \mathrm{C}$ (long-term). The results demonstrated that extracted samples could be analyzed after being
Table 2. Inter-day and intra-day precision and accuracy for the determination of phenobarbital in human plasma

\begin{tabular}{lcccc}
\hline $\begin{array}{l}\text { Nominal } \\
\text { concentration } \\
(\mu \mathrm{g} / \mathrm{mL})\end{array}$ & \multicolumn{2}{c}{ RSD $^{\mathrm{a}}(\%)$} & \multicolumn{2}{c}{ Accuracy (\%) } \\
\hline 0.25 & 1.65 & 3.05 & 102.8 & 103.98 \\
1.8 & 1.14 & 2.65 & 97.46 & 98.51 \\
3.4 & 0.72 & 2.35 & 99.74 & 101.56 \\
\hline
\end{tabular}

${ }^{\mathrm{a}} \mathrm{RSD}=$ Relative standard deviation. ${ }^{\mathrm{b}}$ Mean of six replicates. ${ }^{\mathrm{c}}$ Mean of three days

kept in the autosampler for at least $48 \mathrm{~h}$ with acceptable precision and accuracy. The results of stability of phenobarbital in human plasma are shown in Table 3.

\section{Pharmacokinetic and statistical analysis}

The mean pharmacokinetic parameters after a single $100 \mathrm{mg}$ oral dose administration of test and reference products to nineteen healthy volunteers are presented in Table 4 .

No period effect was observed in the pharmacokinetic parameters studied (data not shown). The curve of the mean phenobarbital plasma concentration versus time obtained after a single oral dose of each phenobarbital formulation is shown in Figure 3. The individual overlays of plasma concentration - time profiles of phenobarbital after oral administration of Test (a) and Reference (b) in healthy volunteers are shown in Figure 4.

At any of the evaluation times, the mean values and the concentrations of phenobarbital seemed non significant differences between the individual subjects studied after the administration of each of the 2 formulations. The mean $\mathrm{C}_{\max }$, obtained at 1.49 and $1.92 \mathrm{~h}$, were 3.22 and $3.11 \mu \mathrm{g} / \mathrm{mL}$ for test and reference formulations, respectively. These values of $\mathrm{C}_{\max }$ were higher than that reported in the literature for the same tablet dosage as $2.30 \mu \mathrm{g} / \mathrm{mL}$, and were similar for the $\mathrm{T}_{\max }{ }^{24}$

Further statistical analysis of pharmacokinetic variables that described the early and total exposure to phenobarbital showed

Table 3. Stability of human plasma samples of phenobarbital

\begin{tabular}{lccc}
\hline Stability condition & $\begin{array}{c}0.25 \mu \mathrm{g} / \mathrm{mL} \\
\left(\mathrm{mean}^{\mathrm{a}} \pm \mathrm{RSD}^{\mathrm{b}}\right)\end{array}$ & $\begin{array}{c}1.8 \mu \mathrm{g} / \mathrm{mL} \\
\left(\mathrm{mean}^{\mathrm{a}} \pm \mathrm{RSD}^{\mathrm{b}}\right)\end{array}$ & $\begin{array}{c}3.4 \mu \mathrm{g} / \mathrm{mL} \\
\left(\mathrm{mean}^{\mathrm{a}} \pm \mathrm{RSD} \mathrm{R}^{\mathrm{b}}\right)\end{array}$ \\
\hline Fresh samples (zero cycle, \%) & $103.92 \pm 1.31$ & $97.02 \pm 4.04$ & $95.86 \pm 1.52$ \\
Freeze-thaw stability (three cycles, $\left.-80^{\circ} \mathrm{C}, \%\right)$ & $103.43 \pm 1.64$ & $91.82 \pm 2.45$ & $95.35 \pm 1.82$ \\
Short-term stability $(8 \mathrm{~h}$, room temperature, \%) & $101.2 \pm 1.34$ & $97.46 \pm 2.85$ & $99.12 \pm 2.68$ \\
Long-term stability $\left(100\right.$ days, $\left.-80^{\circ} \mathrm{C}, \%\right)$ & $96.97 \pm 3.25$ & $92.93 \pm 2.05$ & $95.42 \pm 3.49$ \\
Post-preparative stability $\left(48 \mathrm{~h}, 4^{\circ} \mathrm{C}, \%\right)$ & $97.73 \pm 1.98$ & $97.62 \pm 3.61$ & $100.84 \pm 3$ \\
\hline
\end{tabular}

${ }^{\mathrm{a}}$ Mean of three replicates. ${ }^{\mathrm{b}} \mathrm{RSD}=$ Relative standard deviation

Table 4. Mean pharmacokinetic parameters obtained from 19 healthy volunteers after a single $100 \mathrm{mg}$ oral dose administration of phenobarbital

\begin{tabular}{lccccccc}
\hline Formulation & Parameter & Mean & $\mathrm{SD}^{\mathrm{a}}$ & Minimum & Mediam & Maximum & $\mathrm{RSD}^{\mathrm{b}}(\%)$ \\
\hline \multirow{3}{*}{ Reference } & $C_{\max }(\mu \mathrm{g} / \mathrm{mL})$ & 3.11 & 0.65 & 2.16 & 2.80 & 4.36 & 21.1 \\
& $T_{\max }(\mathrm{h})$ & 1.92 & 1.81 & 0.25 & 1.5 & 8 & 94.35 \\
& $\mathrm{AUC}_{(0-\mathrm{t})}(\mu \mathrm{g} \mathrm{h} / \mathrm{mL})$ & 148.13 & 21.98 & 103.93 & 150.86 & 193.77 & 14.84 \\
\multirow{2}{*}{ Test } & $C_{\max }(\mu \mathrm{g} / \mathrm{mL})$ & 3.22 & 0.68 & 2.32 & 3.19 & 4.69 & 21.26 \\
& $T_{\max }(\mathrm{h})$ & 1.49 & 1.3 & 0.25 & 1 & 4 & 87.63 \\
& $\mathrm{AUC}_{(0-\mathrm{t})}(\mu \mathrm{g} \mathrm{h} / \mathrm{mL})$ & 147.35 & 20.52 & 109.78 & 151.69 & 175.89 & 13.93 \\
\hline
\end{tabular}

${ }^{\mathrm{a}} \mathrm{SD}=$ Standard deviation. ${ }^{\mathrm{b}} \mathrm{RSD}=$ Relative standard deviation 


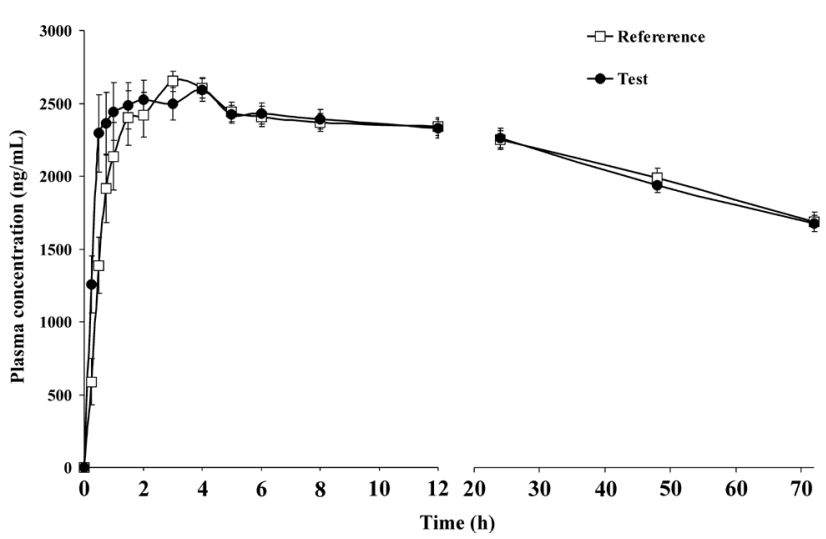

Figure 3. Mean plasma concentration - time profile of phenobarbital after a single $100 \mathrm{mg}$ oral dose administration to 19 healthy volunteers. The vertical bars represents the standard error of the mean

point estimates of the geometric means ratios of $\mathrm{C}_{\max }$ and $\mathrm{AUC}_{(0-\mathrm{t})}$ (phenobarbital test vs. phenobarbital reference) to be $103.93 \%(90 \%$ CI: 97.04-111.32) and 99.62\% (90\% CI: 97.47-101.82), respectively (Table 5). The relative standard deviation (RSD) and the power were 12.19 and $99.94 \%$ for $\mathrm{C}_{\max }$ and 3.86 and $99.98 \%$ for $\mathrm{AUC}_{(0-\mathrm{t}) .}$ For $\mathrm{T}_{\max }$ values of each subject, the nonparametric Wilcoxon test were applied to the differences from test and reference and no significant differences $(P=0.05)$ were found between the two formulations evaluated. The nonparametric $90 \%$ CI for $\mathrm{T}_{\max }$ difference of Test and Reference for women and men were $(-1.5 ; 0.12)$ and $(-1.12 ; 1)$, respectively.
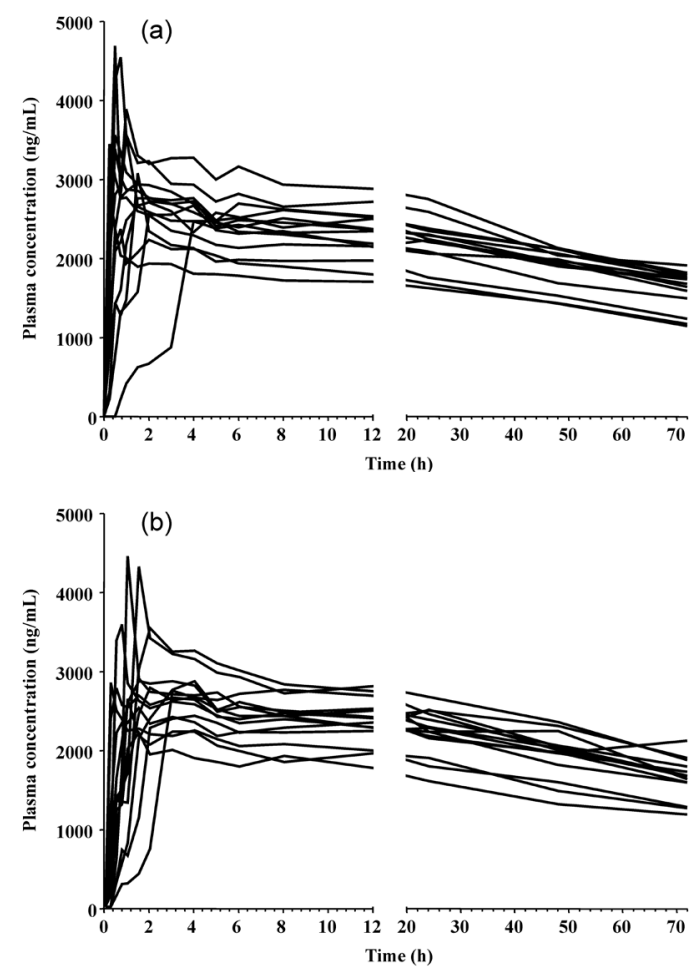

Figure 4. The individual overlay of plasma concentration - time profiles of phenobarbital after a single $100 \mathrm{mg}$ oral dose administration of Test (a) and Reference (b) formulations in healthy volunteers

Table 5. Geometric mean of the $C_{\max }, \mathrm{AUC}_{(0-\mathrm{t})}$ and $C_{\max } / \mathrm{AUC}_{(0-\mathrm{t})}$ ratios (test/reference formulations) and the respective $90 \%$ confidence intervals (CI), after a single $100 \mathrm{mg}$ oral dose administration of phenobarbital

\begin{tabular}{|c|c|c|c|c|}
\hline \multirow[b]{2}{*}{ Parameter } & \multicolumn{4}{|c|}{ Parametric analysis $n=19$} \\
\hline & $\begin{array}{c}\text { Geometric Mean Ratio } \\
(\%)\end{array}$ & $90 \% \mathrm{CI}$ & $\begin{array}{l}\text { Power } \\
(\%)\end{array}$ & $\begin{array}{c}\text { Intra-subject RSD } \\
(\%)\end{array}$ \\
\hline$C_{\max }(\mu \mathrm{g} / \mathrm{mL})$ & 103.93 & $97.04 ; 111.32$ & 99.94 & 12.19 \\
\hline $\mathrm{AUC}_{(0-\mathrm{t})}(\mu \mathrm{g} \mathrm{h} / \mathrm{mL})$ & 99.62 & $97.47 ; 101.82$ & 99.98 & 3.86 \\
\hline \multirow{2}{*}{$C_{\max } / \mathrm{AUC}_{(0-\mathrm{t})}$} & 104.32 & $98.09 ; 110.96$ & 99.98 & 10.93 \\
\hline & \multicolumn{4}{|c|}{ Nonparametric $90 \%$ CI for Tmax difference of Test and Reference } \\
\hline $\mathrm{T}_{\max }(\mathrm{h})$ & Median & $90 \% \mathrm{CI}$ & \multicolumn{2}{|c|}{ Exact Confidence Level } \\
\hline \multirow[t]{2}{*}{ Difference (T-R) } & -0.31 & $-0.75 ; 0.12$ & & \\
\hline & \multicolumn{4}{|c|}{ Men - Parametric analysis $n=8$} \\
\hline Parameter & $\begin{array}{c}\text { Geometric Mean Ratio } \\
(\%)\end{array}$ & $90 \% \mathrm{CI}$ & $\begin{array}{l}\text { Power } \\
(\%)\end{array}$ & $\begin{array}{c}\text { Intra-subject RSD } \\
(\%)\end{array}$ \\
\hline$C_{\max }(\mu \mathrm{g} / \mathrm{mL})$ & 106.99 & $94.82 ; 120.73$ & 92.53 & 12.07 \\
\hline $\mathrm{AUC}_{(0-\mathrm{t})}(\mu \mathrm{g} \mathrm{h} / \mathrm{mL})$ & 98.07 & $93.72 ; 102.62$ & 99.98 & 4.52 \\
\hline \multirow{2}{*}{$C_{\max } / \mathrm{AUC}_{(0-\mathrm{t})}$} & 109.1 & $100.53 ; 118.4$ & 99.25 & 8.17 \\
\hline & \multicolumn{4}{|c|}{ Nonparametric $90 \%$ CI for Tmax difference of Test and Reference } \\
\hline $\mathrm{T}_{\max }(\mathrm{h})$ & Median & $90 \% \mathrm{CI}$ & & ice Level \\
\hline \multirow[t]{2}{*}{ Difference (T-R) } & -0.12 & $-1.5 ; 0.12$ & & \\
\hline & \multicolumn{4}{|c|}{ Women - Parametric analysis $n=11$} \\
\hline Parameter & $\begin{array}{c}\text { Geometric Mean Ratio } \\
(\%)\end{array}$ & $90 \% \mathrm{CI}$ & $\begin{array}{c}\text { Power } \\
(\%)\end{array}$ & $\begin{array}{c}\text { Intra-subject RSD }{ }^{\mathrm{a}} \\
(\%)\end{array}$ \\
\hline$C_{\max }(\mu \mathrm{g} / \mathrm{mL})$ & 100.84 & $91.3 ; 111.36$ & 97.6 & 12.71 \\
\hline $\mathrm{AUC}_{(0-\mathrm{t})}(\mu \mathrm{g} \mathrm{h} / \mathrm{mL})$ & 100.33 & $97.7 ; 103.04$ & 99.99 & 3.39 \\
\hline \multirow{2}{*}{$C_{\max } / \mathrm{AUC}_{(0-\mathrm{t})}$} & 100.5 & $91.06 ; 110.93$ & 97.7 & 12.62 \\
\hline & \multicolumn{4}{|c|}{ Nonparametric $90 \%$ CI for Tmax difference of Test and Reference } \\
\hline $\mathrm{T}_{\max }(\mathrm{h})$ & Median & $90 \% \mathrm{CI}$ & & ice Level \\
\hline Difference (T-R) & -0.5 & $-1.12 ; 1$ & & \\
\hline
\end{tabular}

RSD = Relative standard deviation 
The nonparametric Wilcoxon test was applied to $\mathrm{T}_{\max }$ differences of men and women and it has present not significant difference between men and women for $\mathrm{T}_{\max }(p$ value $=0.279)$.

\section{CONCLUSION}

A specific LC method, with a single step liquid-liquid extraction procedure, has been developed and validated for the determination of phenobarbital in human plasma supporting a pharmacokinetic and bioequivalence study. The statistical analysis demonstrated that none of the parameters accepted for drug bioavailability $\left(\mathrm{AUC}_{(0-\mathrm{t})}\right.$ and $\left.\mathrm{C}_{\max }\right)$ were not significantly different between the treatments for the single dose data. Moreover, it indicated that the two pharmaceutical products showed similar bioavailability profiles and therefore are considered bioequivalent with regard to the extent and rate of absorption and, interchangeable as well, for clinical and therapeutic purposes.

\section{ACKNOWLEDGEMENTS}

The authors wish to thank Cristália Produtos Químicos Farmacêuticos (São Paulo, Brazil) for the support.

\section{REFERENCES}

1. Kwan, P.; Brodie, M. J.; N. Engl. J. Med. 2000, 342, 314.

2. Brodie, M. J.; French, J. A.; Lancet 2000, 356, 323.

3. Wang, W. Z.; Wu, J. Z.; Ma, G. Y.; Dai, X. Y.; Yang, B.; Wang, T. P.; Yuan, C. L.; Hong, Z.; Bell, G. S.; Prilipko, L.; de Boer, H. M.; Sander, J. W.; Lancet Neurol. 2006, 5, 46.

4. Kwan, P.; Brodie, M. J.; Epilepsia 2004, 45, 1141.

5. WHO; Initiative of support to people with epilepsy, Geneva: World Health Organization, 1990.

6. Subramanian, M.; Birnbaum, A. K.; Remmel, R. P.; Ther. Drug Monit. 2008, 30, 347.

7. Kanazawa, H.; Konishi, Y.; Matsushima, Y.; Takahashi, T.; J. Chromatogr., A 1998, 797, 227.

8. Peters, F. T.; Jung, J.; Kraemer, T.; Maurer, H. H.; Ther. Drug Monit. 2005, 27, 334 .

9. Lee, K. J.; Heo, G. S.; Kim, N. J.; Moon, D. C.; J. Chromatogr. 1992 $608,243$.

10. Martín-Biosca, Y.; Sagrado, S.; Villanueva-Camãnas, R. M.; MedinaHernández, M. J.; Biomed. Chromatogr. 2000, 14, 113.
11. Queiroz, R. H. C.; Bertucci, C.; Malfará, W. R.; Dreossi, S. A. C.; Chaves, A. R.; Valério, D. A. R.; Queiroz, M. E. C.; J. Pharm. Biomed. Anal. 2008, 48, 428.

12. Matar, K. M.; Nicholls, P. J.; Tekle, A.; Bawazir, S. A.; Al-Hassan, M. I.; Ther. Drug Monit. 1999, 21, 559.

13. Dutov, A. A.; Temnikova, I. V.; Fedotova, A. A.; Gol'tvanitsa, G. A.; Eksp. Klin. Farmakol. 1999, 62, 53.

14. Johansen, K.; Krough, M.; Andresen, A. T.; Cristophersen, A. S.; Lehne, G.; Rasmussen, K. E.; J. Chromatogr., B: Biomed. Sci. Appl. 1995, 669, 281.

15. Romanyshyn, L. A.; Wichmann, J. K.; Kurcharczyk, N.; Shumaker, R. C.; Ward, D.; Sofia, R. D.; Ther. Drug Monit. 1994, 16, 90.

16. Richard, L.; Leducq, B. ; Baty, C.; Jambou, J.; Ann. Biol. Clin. 1989, 47, 79.

17. Berg, J. D.; Buckley, B. M.; Ann. Clin. Biochem. 1987, 24, 488.

18. Kushida, K.; Ishizaki, T.; J. Chromatogr. 1985, 338, 131.

19. Chun-Lai, M.; Zheng, J.; Yang, J.; Xiao-Jin, S.; Chromatographia 2007, 65, 267.

20. Cavazos, M. L. S.; Cruz, V. T.; Torres, N. W.; López, A. P.; J. Liq. Chromatogr. Relat. Technol. 2005, 28, 693.

21. Sanches, C.; López, K. V.; Omosako, C. E.; Bertoline, M. A.; Pereira, M. D.; Santos, S. R. C. J.; Lat. Am. J. Pharm. 2008, 27, 485.

22. Vermeij, T. A.; Edelbroek, P. M.; J. Chromatogr., B: Anal. Technol. Biomed. Life Sci. 2007, 857, 40.

23. Ceccato, A.; Boulanger, B.; Chiap, P.; Hubert, P.; Crommen, J.; J. Chromatogr., A 1998, 819, 143.

24. Yska, J. P.; Essink, G. W. G.; Bosch, F. H.; Lankhaar, G.; van Sorge, A. A.; Pharm. World Sci. 2000, 22, 67.

25. ANVISA, Diário Oficial da União, Poder Executivo, 02/06/2003; Guia para Validação de Métodos Analíticos e Bioanalíticos, Brasil, 2003.

26. FDA, Center for Drug Evaluation and Research, US Department of Health and Human Services, Guidance for Industry; Bioanalytical Method Validation, 2001.

27. ANVISA, Diário Oficial da União, Poder Executivo, 19/04/2006; Guia para Provas de Biodisponibilidade Relativa/Bioequivalência de Medicamentos, Brasil, 2006.

28. FDA, Center for Drug Evaluation and Research, US Department of Health and Human Services, Guidance for Industry; Bioavailability and Bioequivalence Studies for Orally Administered Drug Products General Considerations, 2002.

29. Chow, S. C.; Liu, J. P.; Design and Analysis of Bioavailability and Bioequivalence Studies, $2^{\text {nd }}$ ed., Marcel Dekker, Inc.: New York, 2000. 